\title{
CA.R.PE.DI.E.M. (Cardio-Renal Pediatric Dialysis Emergency Machine): evolution of continuous renal replacement therapies in infants. A personal journey
}

\author{
Claudio Ronco • Francesco Garzotto • Zaccaria Ricci
}

Received: 12 January 2012 /Revised: 4 April 2012 / Accepted: 4 April 2012 /Published online: 26 May 2012

(C) IPNA 2012

\begin{abstract}
Pedriatric acute kidney injury (AKI) is a welldescribed clinical syndrome that is characterized by a reduction of both the urine output and glomerular filtration rate. AKI in critically ill children is typically associated with multiple organ dysfunction. A dramatic increase in the incidence of AKI in pediatric intensive care units has been observed in the last 10 years. Unfortunately, the absence of sufficiently effective preventive and therapeutic measures at the present time has limited significant improvements in AKI care. Morality in patients with severe AKI remains unacceptably high ( $>50 \%$ ), with renal replacement therapy (RRT) remaining the most effective form of support for these patients. Despite technological advances during the last 10 years which have resulted in the development of the so-called "third-generation dialysis machines" that are characterized by the highest level of safety and accuracy, a truly pedriatric RRT system has never been developed. Consequently, dialysis/hemofiltration in critically ill children is currently performed by adapting adult systems to the much smaller pediatric patients. In particular, research in this field should focus on children weighing less than $10 \mathrm{~kg}$
\end{abstract}

C. Ronco $(\bowtie) \cdot$ F. Garzotto

Department of Nephrology, Dialysis and Transplantation,

International Renal Research Institute Vicenza, San Bortolo Hospital,

Viale Rodolfi 36100,

Vicenza, Italy

e-mail: cronco@goldnet.it

Z. Ricci

Department of Cardiology and Cardiac Surgery, Pediatric Cardiac Intensive Care Unit, Bambino Gesù Children's Hospital,

Piazza S Onofrio 4,

00165, Rome, Italy

e-mail: z.ricci@libero.it for whom the delivery of RRT is a clinical and technological challenge. We describe here the evolution of pediatric RRT during the last 30 years and report in detail on the CARPEDIEM project, which has recently been established to finally provide neonates and infants with a reliable dialysis machine that is specifically designed for this age group.

Keywords Continuous hemofiltration - Acute renal failure · Pediatric dialysis · Perinatal ARF · Pediatric CRRT . Pediatric acute kidney injury

\section{Introduction}

The syndrome currently identified as acute kidney injury (AKI), presents a well-known clinical picture dominated by an abrupt decrease in renal function with diminished urine output, edema, (salt and water overload), hypertension, vomiting, lethargy (uremic encephalopathy), and mild to severe abnormal laboratory test results. This condition may be managed with conservative measures, especially when urine output is maintained, but management may also require extreme measures, such as the initiation of dialysis. Etiology is often multifactorial, including cardiac diseases, sepsis, dehydration, oncologic conditions, and specific pediatric renal disorders.

While the clinical syndrome of AKI has not changed over time, due to advances in critical care, many of the small infants currently receiving care have a significantly higher illness severity than those in the past. Furthermore, AKI today is frequently part of a multiple organ dysfunction syndrome (MODS), with the smaller pediatric patients being sicker and presenting with a more complicated clinical picture than years ago [1]. Recent epidemiological studies utilizing pediatric AKI classification systems have confirmed that the presence of AKI in critically ill pediatric 
children represents an independent risk factor associated with mechanical ventilation, increased length of stay in intensive care units and hospital, and mortality [2].

Here we report on AKI management in infants and children, based on our 30-year experience of research in the field, describing our contribution to the development of new devices and new equipment, especially in the area of continuous renal replacement therapies (CRRT) [3].

\section{The birth of CRRT in infants and children}

In the $1980 \mathrm{~s}$, recent advances in technology made intermittent hemodialysis (HD) possible even in small patients. This technique, however, was difficult and not routinely applied [4]. Peritoneal dialysis (PD), however, had already been used for blood purification in infants and had produced some positive clinical results [4]. In fact, in these patients severe cardiovascular instability, respiratory problems, and other medical complications often precluded HD. Still, PD was technically impossible or undesirable in cases of recent abdominal surgery and skin infection. PD was often carried out manually, with possible errors, although significant improvements were achieved with specific pediatric sets developed by our group in the early 1980s (Fig. 1). Moreover, severe fluid overload could not effectively be treated by PD because of its low ultrafiltration (UF) capacity and the hyper-permeability of the neonatal peritoneal membrane, often leading to severe hyperglycemia. In all these conditions, an alternative treatment was needed.

Continuous arterio-venous hemofiltration (CAVH) was a simple method for blood purification and body fluid control originally described by Kramer et al. in adults in 1977 [5]. In this classic system, a small hemofilter is connected to an artery and a vein, and a simple arterio-venous hydrostatic pressure gradient generated by the heart moves the blood through the circuit, producing slow continuous UF. Blood purification is mainly achieved by convection. Replacement of the ultrafiltrate by substitution solutions contributes to lower solute levels in the blood. No pumps are used in this classic method, and the system operates with low blood flows and low transmembrane pressures (TMP) [6]. In Vicenza, CAVH has been widely used in adults since 1979 as an alternative treatment for critically ill patients in which HD or PD is contraindicated or precluded. We contributed to the evolution of the technique and the deeper understanding of $\mathrm{CAVH}$, leading the investigation towards new devices and specific hardware $[7,8]$. Although we were not a pediatric nephrology division, we received recurrent requests from the department of pediatric surgery for the immediate development of renal replacement therapy (RRT), particularly RRT suitable for neonates developing AKI after cardiac surgery. Our experience suggested that simplicity, rapid application, and good clinical tolerance demonstrated by CAVH in adults could also make it a reliable treatment for infants and children [9]. In these patients, the technique could offer special advantages in terms of low priming volume of the extracorporeal circuit, low rate of heparinization, low blood flow, and slow continuous removal of isotonic fluid. The realization of a pediatric CAVH became reality thanks to a fruitful collaboration with Prof. Juan Bosch at Mount Sinai Hospital in New York and Eng. Luciano Fecondini, the head of R\&D of Amicon Corporation (Limerick, Ireland). We originally had four small prototype filters with only few hollow fibers intended to be used to separate plasma water from blood in the laboratory. We created a modified CAVH circuit with shortened blood lines and connected the small filter (minifilter) and the circuit to an artery and a vein. This circuit was able to run for 48-72 $\mathrm{h}$ in the fourth patient treated in Vicenza and the first such patient in the world. Heparin and substitution fluids were administered according to the fluid balance requirements. An average UF rate of $0.9 \mathrm{ml} / \mathrm{min}$ was achieved by this pioneering system. Figure 2 is a photograph made of the first CAVH treatment carried out at the San Bortolo Hospital in Vicenza. The results in these four patients were subsequently published as the first application of CAVH in neonates [9].

\section{The evolution of CRRT in infants and children}

The initial experience led to an immediate evaluation of the requirements for an adequate $\mathrm{CAVH}$ in infants, namely, a reliable vascular access, adequate technical devices and supplies, specific extracorporeal circuits, precise UF control systems, compatible fluids for replacement, adequate anticoagulation regimens, accurate monitoring systems to improve quality of management, safety, and performance.

\section{Vascular access}

An adequate vascular access in CAVH was required to generate the arterio-venous hydrostatic gradient needed to move the blood through the filter [10]. Shortness and large diameter of the cannulas were critical to achieve a good blood flow while avoiding unnecessary pressure loss. Flexibility without any reduction of the inner lumen of the cannula and good clinical tolerance were two other important features of the vascular access. Several vascular access routes were been utilized in infants in the early 1980s, including umbilical vessels and brachial artery or femoral artery cannulation (with surgical isolation of the artery). Flexible Teflon cannulas (18-20 gauge) that were 20-25 mm long were generally employed. Mean arterial pressure in the newborn generally ranged from 35 to $50 \mathrm{mmHg}$, resulting in blood flows ranging from 


\section{PRECISET}

\section{A CLOSED SYSTEM FOR PEDIATRIC I.P.D. *}

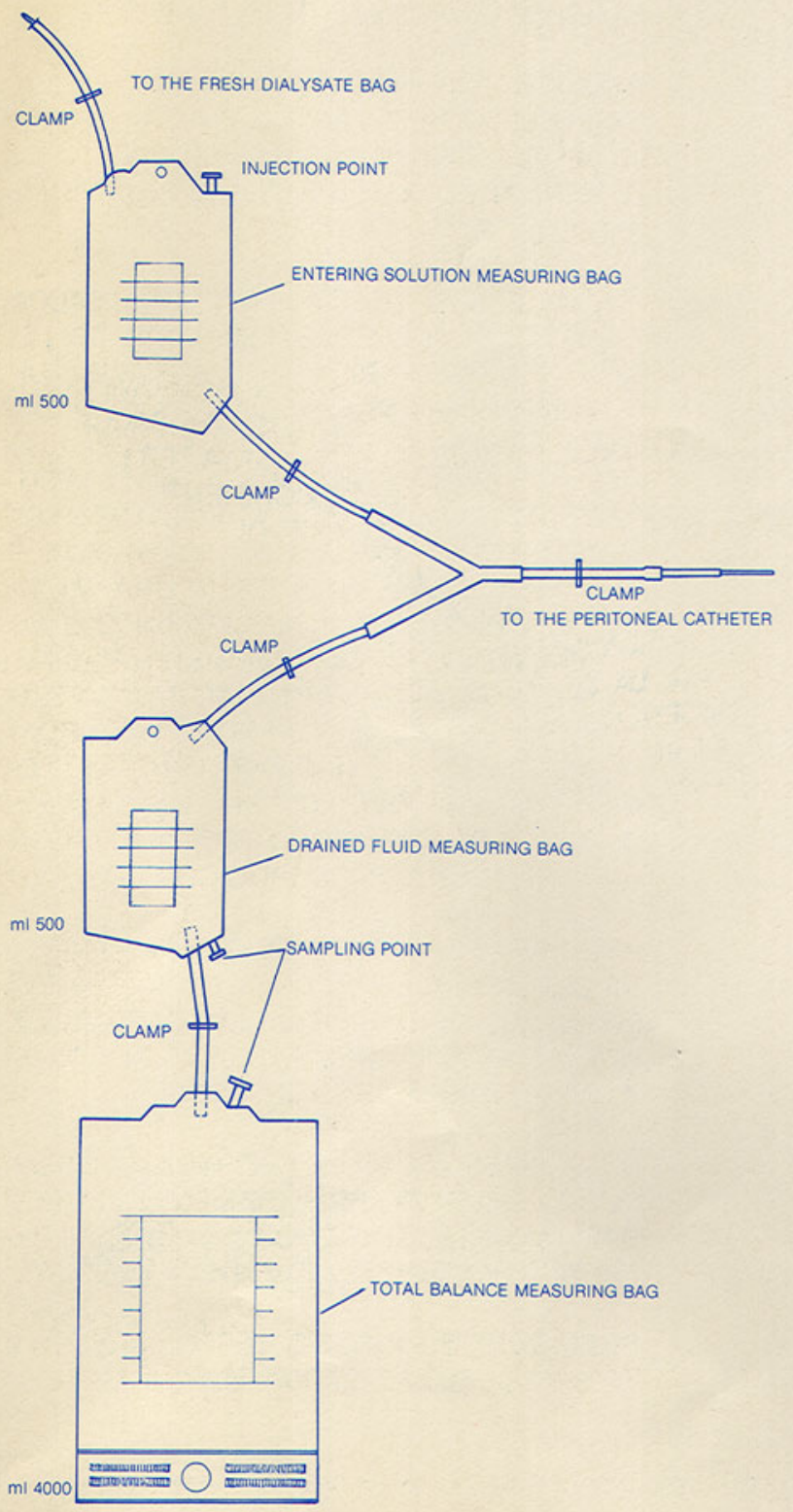

THE LACK OF TECNICAL DEVICES AND EQUIP. MENTS MAKES PERITONEAL DIALYSIS A METHOD NOT SO USED IN CHILDREN AS IN ADULTS.

PRECISET A NEW CLOSED SYSTEM FOR PERITONEAL DIALYSIS IN CHILDREN PERMITS THE TREATMENT OF ACUTE RENAL FAILURE ALSO IN THOSE INTENSIVE CARE DEPARTMENTS WHERE HEMODIALYSIS IS NOT ACHIEVABLE AND IS PARTICULARLY USEFUL FOR SMALL. SEIZED PATIENTS.

AT THE BEGINNING OF THE TREATMENT A FULL BAG (2 L) IS CONNECTED WITH PRECI. SET CONSISTING IN TWO PARTS: THE INFLOW IS PROVIDED WITH A SMALL BAG (300 ML) FOR THE MEASUREMENT OF SOLUTION ENTERING THE PERITONEUM. THE OUTFLOW IS SIMILAR TO THE INFLOW BUT TERMINATES WITH AN EMPTY BAG (3 L). FILLING AND EMPTYING OF THIS VOLUMETRIC SYSTEM ARE CONTROL. LED BY CLAMP. THE TWO SETS ARE LINKED BY AN " $Y$ " JUNCTION AND ARE CONNECTED WITH THE PERITONEAL CATHETER BY A LUERLOCK SYSTEM OR CONICAL JOINT.

PRECISET PERMITS TO MEASURE EXACTLY THE FLUID BALANCE OF EACH EXCHANCE (NO NEED FOR A SCALE) AND GUARANTEES THE MANAGEMENT OF THE PATIENT UNDER STRICTLY ASEPTIC CONDITIONS.

ITS LOW COST, RELIABILITY AND SEMPLICITY MAKE THE SYSTEM EASILY AVAILABLE AND USABLE. A PERITONEAL DIALYSIS SESSION CAN BE INSTITUTED RAPIDLY ALSO IN DEPARTMENTS NOT PARTICULARY EQUIPPED.

FURTHERMORE PRECISET CAN BE USED WITH ALL TYPES OF BAG FOR CONTINUOUS AMBULATORY PERITONEAL DIALYSIS.

* CONCEIVED AT THE VICENZA HOSPITAL (ITALY) DEPT. OF NEPHROLOGY AND DIALYSIS - M.I. n 64281 / B / 1982

Fig. 1 A pioneering pediatric precision set for peritoneal dialysis: the need for accuracy and fluid balance exact monitoring was characterized by the presence of small measuring bags that enabled a strict control of inflows and outflows 


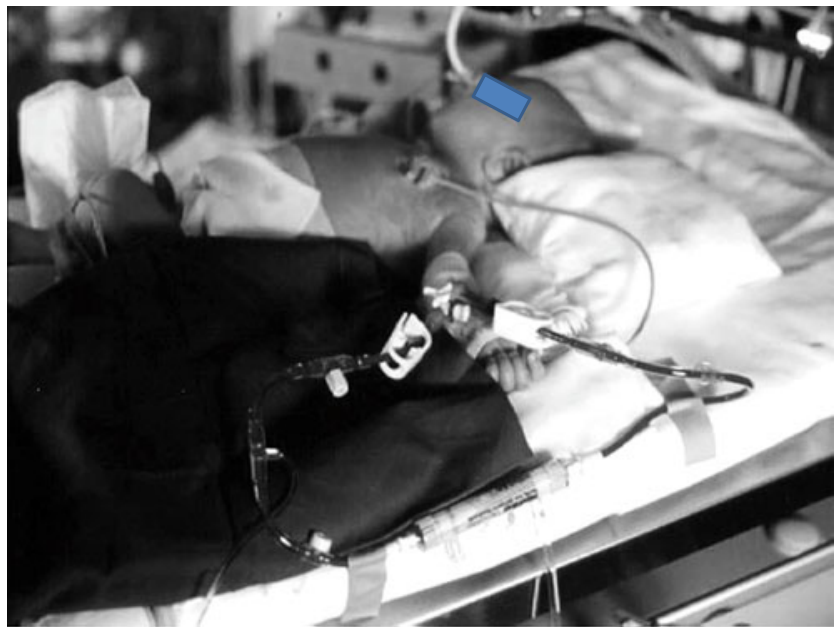

Fig. 2 One of the first neonates treated in Vicenza in the early 1980s. The arterio-venous circuit was achieved either by connecting the radial artery to the basilical vein and/or by connecting the femoral artery to the femoral vein

15 to $40 \mathrm{ml} / \mathrm{min}$ [11]. Cannulation of the brachial or femoral artery in infants led in some cases to distal hypoperfusion of the arm and had to be replaced. The jugular or subclavian veins were the most common route for venous return, while femoral veins were avoided if at all possible.

\section{Extracorporeal circuit}

Blood tubings especially created for CAVH in infants became commercially available: the arterial line had to be as short as possible in order to avoid an unnecessary pressure drop due to high resistance. Since CAVH operates at low pressures, a loss of 5-10 $\mathrm{mmHg}$ along the circuit could seriously affect the UF rate and, consequently, treatment efficiency. For the same reason, a hemofilter with a very low end-to-end pressure drop was required, together with short connections with an adequate diameter between the venous line and the jugular cannula. A port for continuous heparin infusion and another port for arterial blood sampling were designed in the arterial line. The sampling port could also be used for pressure measurements or for the use of the filter in a pre-dilution mode [12].

The venous line presented a port for the infusion of replacement solutions and a venous blood sampling port, both of which could also be used for pressure measurements. At the inlet and outlet of the circuit, wide-bore three-way taps were often placed to exclude the patient's circulation during lavage of the filter with heparinized saline solution. The length of the ultrafiltrate line was fundamental to maximization of the negative pressure exerted on the membrane by the ultrafiltrate column when the collecting bag was placed on the floor. This pressure definitely contributed to increased UF. The low priming volume of the circuit $(<20 \mathrm{ml})$, compared to that of the classic HD systems, further increased the clinical tolerance to the treatment.

\section{The "Minifilters"}

The availability of adequate filters is the key to performing CAVH in infants: low priming volumes have to be coupled with a very low resistance in the blood compartment [13]. These conflicting features could not be achieved with standard fibers and designs, since the small inner diameter associated with a simple reduction in filter size would have resulted in the design of long filters with an elevated internal shear stress. A definite improvement came from the development of a new shorter polysulfone hollow fiber with a larger inner diameter (initially $500 \mu \mathrm{m}$ and subsequently 1100 microns). Our initial clinical tests were carried out with a polysulfone hollow fiber hemofilter (surface area $0.005 \mathrm{~m}^{2}$ ) made by Amicon (Danvers, MA). A few years later, this prototype was improved with a larger surface area $\left(0.015 \mathrm{~m}^{2}\right)$, optimized flow-dynamic design, the addition of a port for dialysate inflow, and was called the "Minifilter". This filter, however, was in some instances still insufficient to guarantee an adequate amount of ultrafiltrate per day. A newer series of minifilters was then developed based on our suggestions, and this design was called the "Minifilter plus". These latter filters were designed to operate with minimal end-to-end pressure drop during $\mathrm{CAVH}$ in infants. The low resistance, which was the main feature of the filters, allowed relatively high flows even at very low perfusion pressures. With these devices, UF ranged between 0.5 and $2 \mathrm{ml} / \mathrm{min}$. Additional factors, such as the negative pressure exerted by the ultrafiltrate column, helped to increase the rate of UF when needed. Previous filters had achieved UF rates of between 0.5 and $1.5 \mathrm{ml} / \mathrm{min}$, with a plateau value at 2.0 $2.5 \mathrm{ml} / \mathrm{min}$ for TMP values between 20 and $70 \mathrm{mmHg}$ and a blood flow of $20-30 \mathrm{ml} / \mathrm{min}$. At similar pressures, the Minifilter Plus achieved significantly higher UF rates (range 3-4 $\mathrm{ml} / \mathrm{min}$ ) with a blood flow of up to $40-50 \mathrm{ml} / \mathrm{min}$. Moreover, the short length of these membranes was a specific design that was conceived to allow filtration to occur over the entire length of the filter, thereby avoiding an early occurrence of filtration pressure equilibrium (when hydrostatic forces driving UF reach equilibrium with increased oncotic pressure derived from de-hydrated hyperproteinemic blood). Hence, the achievement of lower filtration fractions $(<15 \%)$ resulted in ideal operating conditions for the membrane and a consequent extended filter life-span with minimal heparin requirement [14]. Finally, due to the higher sieving properties of the membrane, the concentrations of the various solutes in the UF were identical to plasma water [15], optimizing blood clearance. 
Fluid balancing systems

The removal of large amounts of ultrafiltrate from the patient (1-2 1/day) required the administration of a substitution fluid to maintain an adequate balance. Depending on the patient's requirements, the UF was replaced in part, in whole, or even in excess. The replacement solution was initially administered by manual methods, and semiautomatic or completely automatic systems were employed at later dates [16]. Particular care was given to obtaining the scheduled fluid balance because of the high sensitivity of the neonate to even small variations in body fluid balance and composition. Initially, effluent bags had to be manually weighed. A semi-automatic balancing system became available at a later date, but paradoxically this system increased the potential for significant treatment errors with dangerous consequences due the possibility of error when resetting the balance for the hourly calculation. Only when fully automatic balances were developed did the CRRT machines achieve accurate balance control, with a 24-h recording of fluid exchanges and various safety features, such as the balance error threshold (that stops the CRRT session when exceeded—see below).

\section{The modern practice of CRRT in infants}

When a blood pump was subsequently added to the circuit to perform continuous veno-venous hemofiltration $(\mathrm{CVVH})$ and continuous veno-venous HD (CVVHD), two veins or a single vein with a double lumen catheter were cannulated and all technical aspects learnt during the "CAVH era" seemed to lose importance: circuits became automatic and somewhat safer, fluid balancing became much more accurate, and the research towards miniaturization for the care of smaller patients suddenly stopped due to the greater versatility of modern CRRT machines. At blood flows of between 20 and $80 \mathrm{ml} / \mathrm{min}$, pressure sensors within the blood lines were required to minimize the risk of damage to the vessels and any possible mechanical complication. New blood lines allowed continuous monitoring of the pre- and post-filter pressures, thus making the continuous evaluation of filter and circuit patency possible. The hemofilter could also be incorporated into the cardiopulmonary bypass system after open heart surgery and extracorporeal membrane oxygenation (ECMO).

The indications for RRT in pediatric patients with AKI have changed over the years, and the present trend is towards a wider spectrum of applications, including the prevention of fluid accumulation and MODS [17]. At the present time, PD is the RRT treatment of choice in neonates, unless specific contraindications are present (i.e., peritonitis, abdominal masses, or bleeding). However, in PD, UF and solute clearance occur rather slowly and efficiency is suboptimal.
Extracorporeal dialysis in children can be managed with a variety of modalities, including intermittent $\mathrm{HD}$, and continuous hemofiltration or hemodiafiltration. The choice of dialysis modality to be used is influenced by several factors, including the goals of the dialysis, the unique advantages and disadvantages of each modality, and institutional resources. Intermittent dialysis may not be well tolerated in infants because of rapid rate of fluid removal and of osmotic shifts secondary to sudden solute clearance: this condition is particularly evident in hemodynamically unstable, critically ill pediatric patients [18]. A specific indication to intermittent dialysis is the presence of severe hyperammonemia refractory to medical therapy [19]. Critically ill children, however, are generally treated by CRRT, which allows for slow fluid removal, solute re-equilibration and, probably, the removal of pro-inflammatory mediators.

Critically ill infants with AKI are at the highest risk of water accumulation and inflammation, especially in the postoperative phase. Post-heart surgery patients, for example, receive UF during and/or soon after cardiopulmonary bypass weaning in order to remove water and inflammatory mediators before the harmful effects of inflammation and fluid overload become clinically relevant [20]. It must be remembered that, although commonly performed in several centers, the rationale for utilization of continuous and modified UF is still being debated. Several studies have demonstrated that survivors of CRRT tend to have less fluid overload than non-survivors at the time of CRRT initiation, especially in the setting of MODS, independent of other factors [21, 22]. Interestingly, it is currently not clear if the correction of fluid overload really does change the poor outcomes of these patients. For this reason, in children, equal priority is given to the early correction or prevention of fluid overload, and to dialysis dose.

With regard to the CRRT modality, the solute clearance at the low blood flow rates typically used in pediatric patients has been shown to be similar in post-dilution CVVH and CVVHD [23]. Hemofiltration has specific advantages in HD in terms of the clearance of medium/high-molecular-weight solutes. When there is an increased risk of filter clotting, pre-dilution hemofiltration may, therefore, be the preferred modality. There are no randomized trials guiding the prescription of CRRT in children: a small solute clearance of $2 \mathrm{l} / \mathrm{h} / 1.73 \mathrm{~m}^{2}$ of body surface area (BSA) has been recommended in children [24]. For CVVH, this translates to replacement fluid rates of $1-2 \mathrm{ml} / \mathrm{min}$ in a neonate of $2.5-3.0 \mathrm{~kg}$.

\section{Current challenges and future developments}

AKI in neonates and infants is an "orphan disease"

Pediatric AKI is a dramatic syndrome requiring careful clinical management. To date, despite significant advances 
in critical care technology, a truly pediatric CRRT system has never been developed. Consequently, while currently available CRRT machines have been equipped with pediatric circuits and lines, demonstrating an attempt to comply with the specific requirements of the very small patient, most machines - if not all — are used off label when patients with a body weight of $<15 \mathrm{~kg}$ are being treated. Moreover, a specifically designed neonatal machine has never been conceived. The small number of cases, together with the limited interest of industry to develop a fully integrated device specifically designed for the pediatric population, have made AKI/acute renal failure in infants and neonates an "orphan disease".

\section{Current CRRT technology is inadequate}

Current CRRT machines present with significant limitations for the pediatric population and, in some cases, severe complications have occurred. In current practice, the clinical application of dialysis equipment to pediatric patients is substantially "adapted" to smaller patients, with great concerns about the outcomes and side effects of such extracorporeal therapy. Under these conditions, in contrast to adult critically ill patients who receive renal support with modern devices and very strict safety features, smaller patients cannot rely on a very accurate delivery of therapy, especially in terms of fluid balance. In addition, current dialysis monitors and CRRT machines are not designed to treat a small infant who requires accurate blood flow rates in the range of 10 $50 \mathrm{ml} / \mathrm{min}$ and an hourly UF error of $<5 \mathrm{~g} / \mathrm{h}$. The accuracy of current systems is limited: a recent accurate analysis of the most commonly used machines in the adult setting showed the balance error to be an alarming 20-190 g [25] depending on the machine and on the treatment flow rate (with the lowest flows being the most accurate). Interestingly, machines also have different "reaction times" before a fluid balance error occurs (range 10-20 s), which explains how, in the worst case, more than $500 \mathrm{ml}$ could be excessively removed from a patient within a couple of minutes after three or four unchecked alarm overrides. Remarkably, third-generation machines automatically stop CRRT sessions when a (adjustable) fluid balance error (typically 60 $500 \mathrm{ml}$ ) has been reached within the (adjustable) time unit (typically $3 \mathrm{~h}$ ). Before this feature application, fatal errors often occurred in the very small patient. In a recent personal observation the average fluid removal error in a cohort of small pediatric patients treated with different CRRT set-ups and flow ranges ranged from -0.5 to $3.7 \mathrm{ml} / \mathrm{h}$ [26]. This trend tended to shift from the lowest to the highest error in proportion to the duration of the session, especially when the dialysis machine was applied to the ECMO. During that study, we observed an unintentional daily excess fluid removal of $200 \mathrm{ml}$ in one patient. Furthermore, since manufacturers of dialysis or CRRT machines do not perform specific tests for treatments in patients weighing less than $10-15 \mathrm{~kg}$ and safety features in these patients are not specifically created, legal concerns may arise when operators decide to prescribe these therapies.

\section{The CA.R.PE.DI.E.M. project}

The Cardio-Renal, Pediatric Dialysis Emergency Machine (CARPEDIEM) is a project developed by the Department of Nephrology and International Renal Research Institute of the San Bortolo Hospital in Vicenza (IRRIV) with the aim of creating the basis for the conception of RRT equipment specifically dedicated to newborns and small infants in the weight range of $2.0-9.9 \mathrm{~kg}$ and with an approximate BSA of $0.15-0.5 \mathrm{~m}^{2}$. The total blood volume in such patients ranges from $<200 \mathrm{ml}$ to about 11 , which means that the total body water content varies from 1 to 51 . Under such conditions, priming volumes of the circuits should be reduced to a minimum level, and roller pumps should be able to run at a slow speed, thereby guaranteeing the integrity of the lines (small roller pumps running small tubes are expected to cause a quick decline in their performance) and maintaining an excellent level of flow and balance accuracy.

The ambition of the CARPEDIEM project is to reconsider the technical and clinical expertise accumulated during the "pediatric CAVH era" and to design, with the help of modern miniaturization engineering skills, the first neonatal CRRT monitor. The project has been financed by an unrestricted grant from a non-profit organization [Associazione Amici del Rene di Vicenza (A.A.R.VI)], and the apparatus was conceived in Vicenza and built in Mirandola, Italy with the collaboration of two industrial companies (Bellco, Mirandola, Italy and Medica, Medolla, Italy).

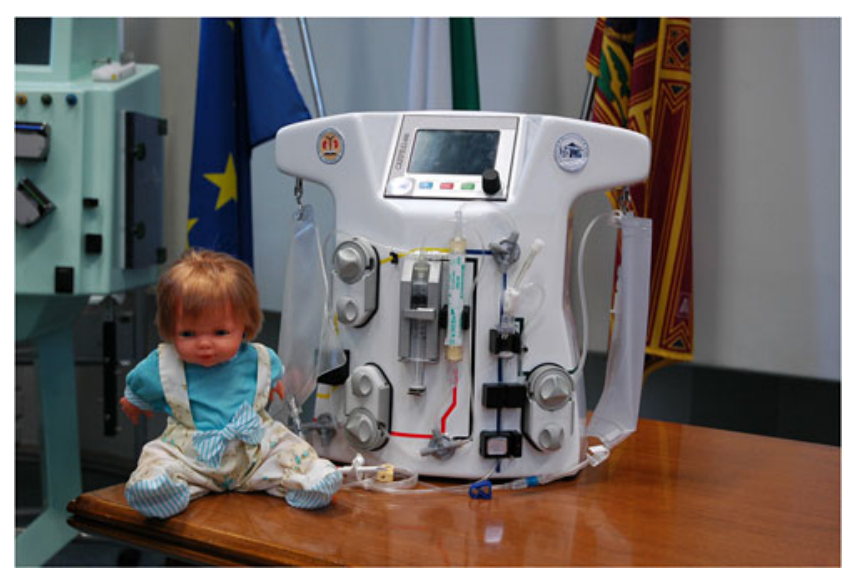

Fig. 3 The Cardio-Renal, Pediatric Dialysis Emergency Machine (CARPEDIEM) measures $44 \overline{(\mathrm{L})} \times 43(\overline{\mathrm{H}}) \times 23(\overline{\mathrm{W}}) \mathrm{cm}$, weighs $13 \mathrm{~kg}$, and is specifically designed as a miniaturized, transportable device 


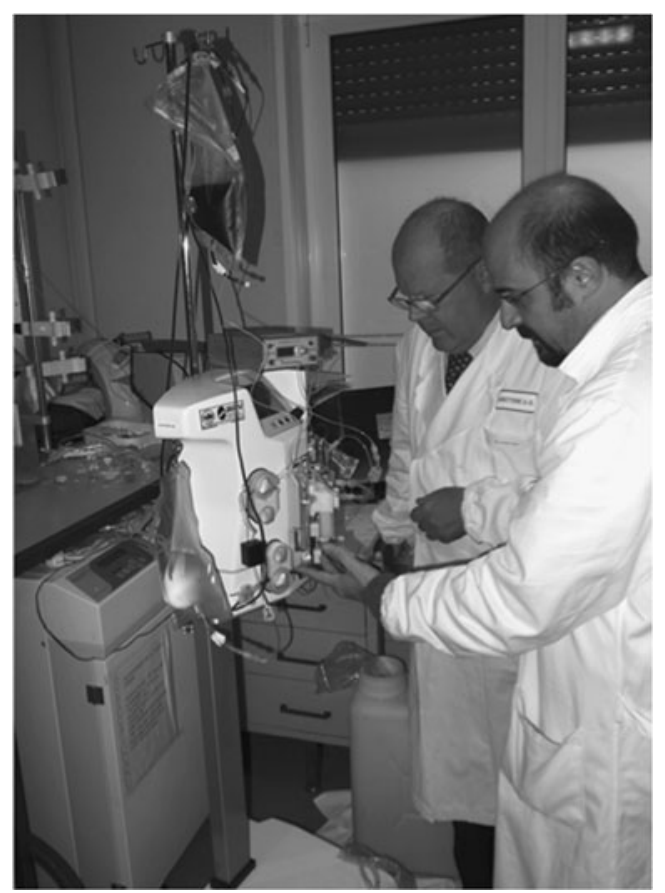

Fig. 4 The first in vitro trial of the CARPEDIEM machine. In this image the machine was running through a 4-French bilumen catheter

Technical features and first in vitro runs of the CARPEDIEM machine

The CARPEDIEM machine (Fig. 3) has been developed as a CRRT platform and has received European Union certification. The machine is now ready for clinical use, and the in vitro testing with catheters of different sizes and at different flow rates has demonstrated how it responds to the required criteria of performance and accuracy.

The CARPEDIEM machine measures $44(\mathrm{~L}) \times 43(\mathrm{H}) \times$ $23(\mathrm{~W}) \mathrm{cm}$, weighs $13 \mathrm{~kg}$, and is specifically designed as a miniaturized, transportable device. It is provided with 6 inches of user interface, three 40-mm-diameter roller pumps, two scales, and three pressure transducers. Blood leakage and the presence of air in the circuit are monitored by two detectors proximal to the effluent line and the return line, respectively. A 20-ml syringe pump for heparin infusion is part of the system. An alarm light atop the machine is present, with three greenyellow-red colors indicating the severity of the problem. The miniaturization effort has currently resulted in the development of three pre-assembled circuits with new polysulphone membranes, each with a surface area of $0.075,0.147$, and $0.245 \mathrm{~m}^{2}$ and priming volumes of $27.2,33.5$, and $41.5 \mathrm{ml}$, with the circuit included (extracorporeal blood volume). The machine automatically detects the specific dialyzer in use and accordingly sets the maximum achievable performance. The treatment set-up is achieved by blood flow, dialysate/hemofiltration, and net UF regulation: these three main treatment characteristics clearly appear in the main page of the user interface. One paddle and three buttons (help, disable alarm, and confirm) are features of the simplified control panel of the machine. It is possible to verify and modify the prescription during the treatment on the user interface. In particular, a net UF target can be chosen at the session start (eventually modifiable) and monitored on-line during the session. The blood pump flow rate ranges from 5 to $50 \mathrm{ml} / \mathrm{min}$. The maximum total achievable UF and dialysis/ hemofiltration rates range from $5 \mathrm{ml} / \mathrm{min}$ with the largest dialyzer, down to $2.5 \mathrm{ml} / \mathrm{min}$ for the smallest dialyzer. This technical set-up is considered to be able to meet the target of small solute clearance of $2 \mathrm{l} / \mathrm{h} / 1.73 \mathrm{~m}^{2}$ of BSA and/or 25 $35 \mathrm{ml} / \mathrm{kg} / \mathrm{h}$ in patients weighing $<10 \mathrm{~kg}$. To ensure accurate fluid balance, the CARPEDIEM is equipped with gravimetric control combined with an excellent scale sensitivity of $1 \mathrm{~g}$ for both infusion and effluent bags. An automatic feedback system continuously adjusts pump speed according to the prescribed and actual delivery of fluid: the difference between prescribed and achieved fluid balance is always kept less than $20 \mathrm{~g} / 24 \mathrm{~h}$. The treatment is terminated when a session fluid balance error of $50 \mathrm{~g}$ is reached.

We recently performed in vitro tests with milk and with bovine blood (hematocrit $35 \%$, protein concentration $5 \mathrm{~g} / \mathrm{dl}$ ) that were both run through 4 and 7 French bilumen catheters (Fig. 4). Circuits were run for $24 \mathrm{~h}$, and no significant changes in flow accuracy were observed. Our tests estimated an excellent accuracy of blood pump flow rate, with an error $<10 \%$, with the
Fig. 5 Relationship between the transmembrane pressure $(T M P)$ and $0,1,2,3,4 \mathrm{ml} / \mathrm{min}$ ultrafiltration at $10,15,20$ $30 \mathrm{ml} / \mathrm{min}$ of blood flow $(Q b)$ through the $0.245 \mathrm{~m}^{2}$ filter. A plateau TMP was reached only at the maximum available filtration flow settings and the lowest blood flow rates $(\mathrm{Qb} 10$ and $15 \mathrm{ml} / \mathrm{min}$ )

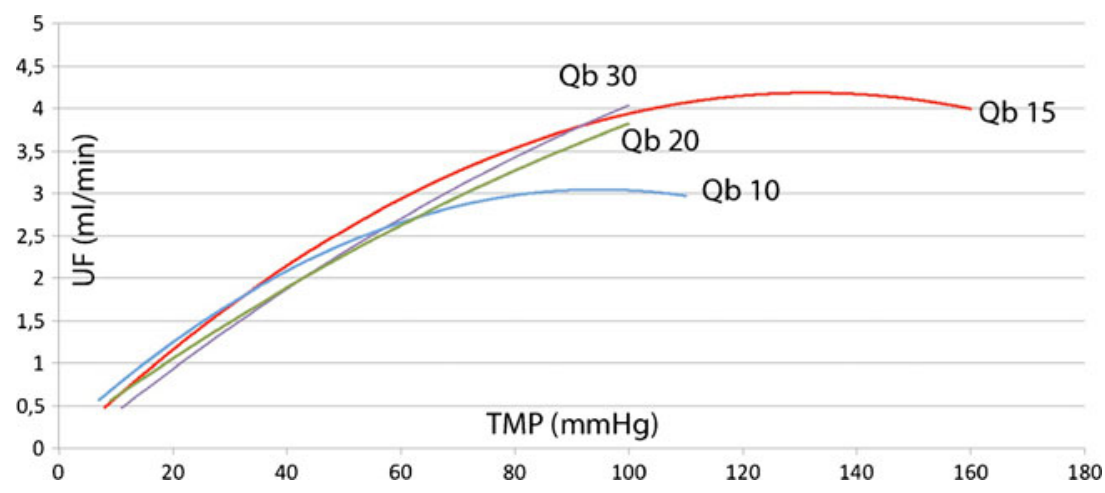


error being slightly higher at slower blood flows. The error in the reinfusion flow ranged from -8 to $+7.5 \%$. Importantly, UF accuracy always remained within the limit of $1 \mathrm{~g} / \mathrm{h}$. The relationship between the TMP and filtration was evaluated at 10 , $15,2030 \mathrm{ml} / \mathrm{min}$ of blood flow and at $0,1,2,3,4 \mathrm{ml} / \mathrm{min}$ of filtration. Interestingly, when the TMP/filtration flow graph was evaluated on the three available filters, we noticed that a plateau TMP (typically reached when the filtration flow rate exceeds membrane capacity) was recorded only at the maximum available filtration flow settings and the lowest blood flow rates (Fig. 5), showing that filters' performance is generally optimized with the CARPEDIEM set-up. Micro-hemolysis was evaluated by measuring the normalized (by hematocrit) index of hemolysis (NIH). We tested three different assembly lines and dialyzers in three tests each: the first with the D050 dialyzer and a blood flow of $40 \mathrm{ml} / \mathrm{min}$; the second with the D150 dialyzer and a blood flow of $50 \mathrm{ml} / \mathrm{min}$; the third without the dialyzer setting and the maximum pump speed. A 1-1 sample of bovine blood (hematocrit $45 \%$ ) was allowed to circulate for $10 \mathrm{~h}$. The observed micro-hemolysis was below the safety level and no difference was observed for the three types of test circuits.

With the current machine set-up, heparin anticoagulation (at the conventional rate of 2-10 international units of unfractionated heparin $/ \mathrm{kg} / \mathrm{h}$ ) will be delivered. It is as yet unknown if the typical prothrombin time of $40 \mathrm{~s}$, utilized in our institution in order to optimize filter patency, will be adequate, or if higher heparin doses will be required.

\section{CARPEDIEM project pathway}

To date, short- and medium-term goals have been achieved. Further steps remain to be accomplished. These include (1) validation of CARPEDIEM use in clinical practice; (2) development of a multicenter trial to define the ideal prescribing and application of neonatal CRRT; (3) actions towards achieving the large-scale production of the machine and its disposable dedicated circuits. The CARPEDIEM project was conceived in Vicenza, but in addition to the pediatric intensive care center in Vicenza, other Italian pediatric cardio-surgical centers (Rome and Milan) are currently participating in the first in vivo CARPEDIEM trial. This network is expected to develop into a multinational study group when the clinical phase comes into place.

\section{Conclusion}

AKI is a severe clinical condition that is further complicated in small children by the peculiar problems of these patients. Early diagnosis, prevention, conservative measures, a multidisciplinary approach, and timely RRT are all part of a common approach that must be undertaken in these highrisk patients. The outcomes may vary significantly depending on the underlying disease, the severity of illness, and the time of intervention. To date, however, outcomes of critically ill children with AKI are poor, and a strategy for improvement is urgently needed. In this scenario, new technological advances, such as miniaturized circuits and membranes and accurate CRRT machines, as well as effective prescription schedules provide promise to the clinician for improving the quality of treatment.

Acknowledgments We are indebted to the Associazione Amici del Rene di Vicenza, and the many generous people and institutions who donated funds for the progress of the CARPEDIEM project, including Arma dei Carabinieri, Stefania Villanova, Giuseppe e Roberta Boschetti, and Banca Popolare di Vicenza. The project is a charityfunded initiative and represents an important step forward for what we consider an "orphan disease".

\section{References}

1. Basu RK, Devarajan P, Wong H, Wheeler DS (2011) An update and review of acute kidney injury in pediatrics. Pediatr Crit Care Med 12:339-347

2. Duzova A, Bakkaloglu A, Kalyoncu M, Poyrazoglu H, Delibas A, Ozkaya O, Peru H, Alpay H, Soylemezoglu O, Gur-Guven A, Bak M, Bircan Z, Cengiz N, Akil I, Ozcakar B, Uncu N, KarabayBayazit A, Sonmez F, Turkish Society for Pediatric Nephrology Acute Kidney Injury Study Group (2010) Etiology and outcome of acute kidney injury in children. Pediatr Nephrol 25:1453-1461

3. Ronco C, Polaschegg HD (2009) History and development of continuous renal replacement therapy. In: Ronco C, Bellomo R, Kellum J (eds) Critical care nephrology, 2nd edn. SaundersElsevier, Philadelphia, pp 1323-1328

4. Potter DE, San Luis E, Wippler JE, Portale AA (1986) Comparison of continuous ambulatory peritoneal dialysis and hemodialysis in children. Kidney Int 30:S11-S14

5. Kramer P, Wigger W, Rieger J, Matthaei D, Scheler F (1977) Arteriovenous hemofiltration: a new and simple method for treatment of overhydrated patients resistant to diuretics. Klin Wschr 55:1121-1125

6. Lauer A, Saccaggi A, Ronco C, Belledonne M, Glabman S, Bosch JP (1983) Continuous artriovenous hemofiltration in the critically ill patient. Ann Intern Med 99:455-461

7. Ronco C, Brendolan A, Bragantini L, La Greca G (1985) Continuous arterio-venous hemofiltration. Contr Nephrol 48:70-78

8. Bartlett R, Bosch JP, Paganini EA, Geronemus R, Ronco C (1987) Continuous arterio-venous hemofiltration. Trans Am Soc Artif Internal Organs 38:345-352

9. Ronco C, Brendolan A, Bragantini L, La Greca G (1986) Treatment of acute renal failure in the newborn by continuous arteriovenous hemofiltration. Kidney Int 29:908-915

10. Olbricht CJ, Schurek HJ, Tytul S, Muller C, Stolte H (1985) Comparison between Scribner shunt and femoral catheters as vascular access for continuous arteriovenous hemofiltration. In: Kramer P (ed) Arteriovenous hemofiltration. Springer, Berlin, pp 57-66

11. Pallone TL, Peterson J (1987) Continuous arteriovenous hemofiltration, an in vivo simulation. Trans Am Soc Artif Internal Organs 33:304-308

12. Ronco C, Brendolan A, Borin D (1986) Continuous arterio-venous hemofiltration in newborns. In: Sieberth H, Mann H (eds) Proc Int Conf on CAVH. Karger, Basel, pp 76-79

13. Ronco C, Bosch JP, Lew S (1986) Technical and clinical evaluation of a new hemofilter for CAVH; Theoretical concepts and practical applications od a different blood flow geometry. In: La 
Greca G, Fabris A, Ronco C (eds) Proc Int Symp on CAVH. Wichtig, Milan, pp 55-61

14. Pappenheimer AM Jr (1953) Passage of molecules through capillary walls. Physiol Rev 33:387-423

15. Ronco C, Brendolan A, Bragantini L, La Greca G (1987) Solute and Water transport during Continuous arterio-venous hemofiltration. Int J Artif Organs 10:179-184

16. Brendolan A, Ronco C, Crepaldi C, Feriani M, Milan M, Fecondini L, La Greca G (1993) Clinical use of a new fluid balancing system: a useful complement to continuous replacement therapies. J Nephrol 6:149-152

17. Bailey D, Phan V, Litalien C, Ducruet T, Mérouani A, Lacroix J, Gauvin F (2007) Risk factors of acute renal failure in critically ill children: a prospective descriptive epidemiological study. Pediatr Crit Care Med 8:29-35

18. Flynn JT (2002) Choice of dialysis modality for management of pediatric acute renal failure. Pediatr Nephrol 17:61-69

19. Picca S, Dionisi-Vici C, Abeni D, Pastore A, Rizzo C, Orzalesi M, Sabetta G, Rizzoni G, Bartuli A (2001) Extracorporeal dialysis in neonatal hyperammonemia: modalities and prognostic indicators. Pediatr Nephrol 16:862-867

20. Berdat PA, Eichenbergera E, Ebella J, Pfammatter JP, Pavlovic M, Zobrist C, Nydegger E, Carrel T (2004) Elimination of proinflammatory cytokines in pediatric cardiac surgery: analysis of ultrafiltration method and filter type. J Thorac Cardiovasc Surg 127:1688-1696
21. Goldstein SL, Somers MJ, Baum MA, Symons JM, Brophy PD, Blowey D, Bunchman TE, Baker C, Mottes T, McAfee N, Barnett J, Morrison G, Rogers K, Fortenberry JD (2005) Pediatric patients with multi-organ dysfunction syndrome receiving continuous renal replacement therapy. Kidney Int 67:653-658

22. Sutherland SM, Zappitelli M, Alexander SR, Chua AN, Brophy PD, Bunchman TE, Hackbarth R, Somers MJ, Baum M, Symons JM, Flores FX, Benfield M, Askenazi D, Chand D, Fortenberry JD, Mahan JD, McBryde K, Blowey D, Goldstein SL (2010) Fluid overload and mortality in children receiving continuous renal replacement therapy: the prospective pediatric continuous renal replacement therapy registry. Am J Kidney Dis 55:316325

23. Parakininkas D, Greenbaum LA (2004) Comparison of solute clearance in three modes of continuous renal replacement therapy. Pediatr Crit Care Med 5:269-274

24. Available at: www.pcrrt.com

25. Ronco C, Ricci Z, Bellomo R, Baldwin I, Kellum J (2005) Management of fluid balance in CRRT: a technical approach. Int J Artif Organs 28:765-776

26. Ricci Z, Morelli S, Vitale V, Di Chiara L, Cruz D, Picardo S (2007) Management of fluid balance in continuous renal replacement therapy: technical evaluation in the pediatric setting. Int $\mathrm{J}$ Artif Organs 30:896-901 